\title{
Knowledge, Attitude and Practice of Community on Traditional Medicine in Jara Town, Bale Zone South East Ethiopia
}

\author{
Ahmed Yasin Mohammed ${ }^{1,}$, Muhammedawel Kasso ${ }^{1}$, Ashebir Demeke \\ ${ }^{1}$ Department of Public Health, College of Medicine and Health Science, Madda Walabu University, Bale Goba, Ethiopia \\ ${ }^{2}$ Department of Psychology, School of Behavioural Studies, Madda Walabu University, Bale Robe, Ethiopia \\ Email address: \\ ahmedyassinmoha@yahoo.com (A. Y. Mohammed) \\ *Corresponding author

\section{To cite this article:} \\ Ahmed Yasin Mohammed, Muhammedawel Kasso, Ashebir Demeke. Knowledge, Attitude and Practice of Community on Traditional \\ Medicine in Jara Town, Bale Zone South East Ethiopia. Science Journal of Public Health. Vol. 4, No. 3, 2016, pp. 241-246. \\ doi: $10.11648 /$ j.sjph.20160403.23
}

Received: April 28, 2015; Accepted: December 10, 2015; Published: May 26, 2016

\begin{abstract}
Traditional medicine is an ancient medical practice that is still widely used in prevention and treatment of various health problems for majority of global population particularly in rural developing countries like Ethiopia. The aim of this study is to assess knowledge, attitude and practice of the community on tradition medicine in Jara town. A community based cross sectional study was carried out in the community of Jara town from April 5 to April 10/2013. Face to face interview was carried out using structured questionnaire. Data were analyzed using SPSS version 20. Frequency and percentages were calculated. The study involved 271 participants recruited by systematic random sampling technique. Participants of the study were interviewed with a structured open and close ended questionnaire. From the total of 271 participants who were identified for the study all of them participated in the study. Two hundred sixty one $(96.3 \%)$ of the respondents answered that they have heard about traditional medicine. One hundred forty eight $(54.61 \%)$ of the respondents think that there are diseases that are not cured by modern medicine while $123(45.38 \%$ ) believe that there are no diseases that cannot be cured by modern medicine. One hundred nineteen $(43.91 \%)$ of our respondents have planned to use traditional medicine in the future. Two hundred (73.8\%) of the respondents have used traditional medicine at least once in their life time. The study concludes that many of the respondents found herbal medicine to be safe, effective and beneficial. Despite many of the respondents believe that herbal medicine rarely produce adverse effect, a few experienced them mildly and moderately.
\end{abstract}

Keywords: Knowledge, Attitude, Practice, Traditional Medicine, Ethiopia

\section{Introduction}

World Health Organization (WHO) defines traditional medicine (TM) as health practices, approaches, knowledge and believes incorporating plant, animal and mineral based medicine, spiritual, manual techniques and exercises, applied singularly or in combination to treat, diagnose and prevent illness and maintain well being [1]. Traditional medicine is still widely accepted and used in prevention and treatments of physical and mental disorder as well as social imbalance, due to its intrinsic qualities, unique and holistic approaches as well as its accessibility. It continues to be the best alternative care available for the majority of the global population, particularly for those in the rural areas of the developing countries [2].

The WHO estimate that in many developed countries, 70$80 \%$ of the population has used some form of alternative or complementary medicine including, homeopathic, naturopathic, traditional oriental and Native American Indian medicine [3]. Traditional medicine has maintained its popularity in all regions of the developing world and its use is rapidly spreading in the industrialized countries. In China for example, traditional herbal preparation account for 30 to $50 \%$ of the total medicine consumption. In Ghana, Mali, Nigeria and Zambia, traditional medicine is the first line of 
treatment for $60 \%$ children. WHO estimates that in several African countries traditional birth attendants (TBAs) assist in the majority of birth $[4,5]$.

In Ethiopia up to $80 \%$ of the population uses traditional medicine (TM) due to the cultural acceptability of healers and local pharmacopeias, the relatives low cost of traditional and difficult access to modern health facilities. In 2000 only $9.45 \%$ of all deliveries in Ethiopia were attended by trained attendants and health workers. The rest were attended by traditional birth attendants or relatives $[6,7]$.

Traditional medicine like herbal medicine, massage, therapeutic dieting, fasting, hydrotherapy and radiant healing therapy are practiced in many parts of Africa. However; given the great diversity of cultures, ethnicities and geographic region with in Africa, it is extremely difficult to make generalization about African traditional medicine. Notwithstanding the challenges and competitions, traditional medicine faced vis-a-vis Western medicine, many Africans, especially those in the rural areas rely on traditional medicine not only for their medicine value and promotion of good health and fortune but also their spiritual well being [8].

The vast majority of Ethiopia population lives in rural areas where the health care coverage low and where existing public sector resources are being stretched to the limits. One of the greatest challenges facing the country is determining how best to narrow the gap between the existing services and the population whose access to them is very limited [9]. A study of pharmaceutical drug use showed that $35 \%$ of the population did not obtain prescribed drugs due to money [10]. However; most traditional medicine are delivered either free or with a relatively low cost which contributes to the use of rural based healers for community primary health care need, The current Ethiopian health care system is primary health care focused $[11,12]$.

The main purpose of this study is to identify gaps in knowledge, attitude and practice of traditional medicine in Jara town. Identifying the gaps will help in educating the population about the benefit and adverse effect of traditional medicine. Finally, it is a base line to concerned bodies to undertake the intervention on the use of traditional medicine, to do further investigations.

\section{Methodology}

\subsection{Study Area, Period and Design}

A community based cross sectional survey study was conducted at Jara town, Bale zone, Oromia region, Southeast Ethiopia from April 5/2013 to April 10/2013.

\subsection{Sample Size Determination}

Sample size was calculated by using sample size determination formula.

$$
n=Z^{2} p(1-p) / d^{2}
$$

Where:

$\mathrm{n}=$ the estimated sample size
$\mathrm{Z}=$ is the standard normal value corresponding to the desired level of confidence

$\mathrm{d}=$ error of precision

$\mathrm{p}=$ people getting health care from traditional medicine that is $80 \%$.

Therefore, adding the non-respondent rate (10\%) the final sample size $=271$

\subsection{Sampling Technique}

There are 1720 households in Jara town and sample size is to be 271. So households were selected by systematic random sampling technique by which every sixth household undergone a face to face interview.

\subsection{Study Variables}

\subsubsection{Dependent Variable}

Knowledge, attitude and practice on traditional medicine

\subsubsection{Independent Variable}

Socio demographic status/factors
- age
-sex
-educational status
-religion
Social factors
-peer influence
-family income
Cultural (related factors)
- relief
-tradition
-ethnicity

\subsection{Data Quality Control}

Face to face interviews were carried out using the questionnaire which was first formulated in English version and then translated in to Afan Oromo. Each questionnaire was checked for incompleteness, missed values and unlikely responses, and then manually cleaned upon such indications. The data was cross checked for consistency and accuracy.

\subsection{Ethical Consideration}

Before data collection procedure, letter of permission was obtained from MWU Research and Community Service Directorate and verbal consent was taken from the study subjects. The respondent right and dignity was also respected in order to keep confidentiality of each respondents' name was not included.

\section{Result}

\subsection{Socio-demographic Characteristics of Study Subject}

From a total of 271 participants who were identified for the study, all of them were participated in the study, yielding the response rate of $100 \%$. One hundred sixty $(59.04 \%)$ of the respondents were males while $111(40.9 \%)$ were females. 
The detail socio-demographic characteristics of the respondents has been portrayed in the table below.

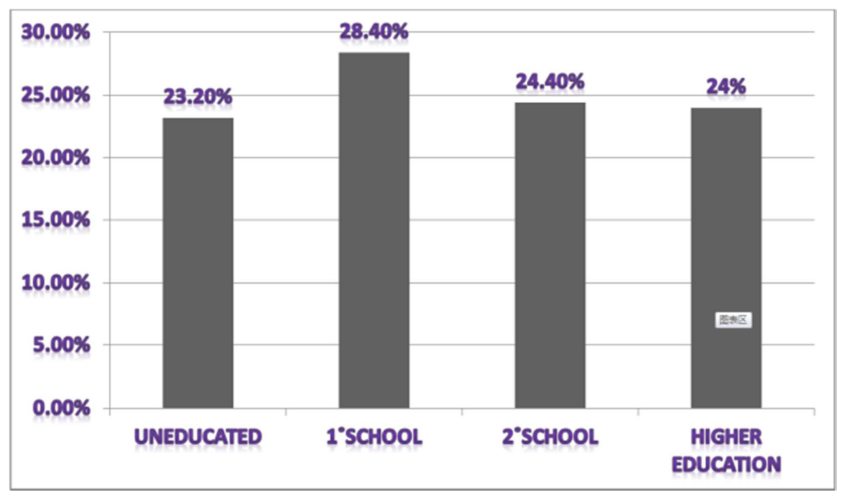

Figure 1. Educational status of the respondents in Jara town, April 2013.

Table 1. Socio-Demographic Characteristics of the respondents; Jara town, Bale Zone, Southeast Ethiopia; April 2013.

\begin{tabular}{|c|c|c|}
\hline Variable & Frequency & Percent \\
\hline \multicolumn{3}{|l|}{ Age } \\
\hline $19-28$ & 77 & $28.4 \%$ \\
\hline $29-38$ & 68 & $25.1 \%$ \\
\hline $39-48$ & 63 & $23.2 \%$ \\
\hline $49-58$ & 37 & $13.6 \%$ \\
\hline $59-68$ & 15 & $5.5 \%$ \\
\hline $69-78$ & 9 & $3.3 \%$ \\
\hline$\geq 79$ & 2 & $0.74 \%$ \\
\hline \multicolumn{3}{|l|}{ Marital status } \\
\hline Married & 207 & $76.4 \%$ \\
\hline separated/divorced & 23 & $8.5 \%$ \\
\hline Widowed & 17 & $6.3 \%$ \\
\hline Single & 24 & $8.8 \%$ \\
\hline \multicolumn{3}{|l|}{ Occupation } \\
\hline house wife & 47 & $17.34 \%$ \\
\hline Farmer & 67 & $24.72 \%$ \\
\hline Government employee & 75 & $27.68 \%$ \\
\hline private employee & 19 & $7.01 \%$ \\
\hline Merchant & 58 & $21.4 \%$ \\
\hline Other & 5 & $1.84 \%$ \\
\hline \multicolumn{3}{|l|}{ Ethnicity } \\
\hline Oromo & 210 & $77.49 \%$ \\
\hline Amhara & 53 & $19.55 \%$ \\
\hline Tigre & 4 & $1.48 \%$ \\
\hline Other & 4 & $1.48 \%$ \\
\hline \multicolumn{3}{|l|}{ Family income per month } \\
\hline low $(\leq 675$ birr $)$ & 48 & $17.71 \%$ \\
\hline Medium (676 - 1675 birr) & 89 & $32.84 \%$ \\
\hline High ( $\geq 1676$ birr) & 134 & $49.44 \%$ \\
\hline \multicolumn{3}{|l|}{ Family size } \\
\hline $1-2$ & 46 & $16.97 \%$ \\
\hline $3-4$ & 98 & $36.16 \%$ \\
\hline $5-6$ & 67 & $24.72 \%$ \\
\hline$\geq 7$ & 60 & $22.14 \%$ \\
\hline
\end{tabular}

\subsection{Knowledge of the Study Subjects on Traditional Medicine}

Two hundred sixty one $(96.3 \%)$ of the respondents answered that they have heard about TM. Of the respondent heard about TM, 36.78\% knew about herbal while 3.06\%, $6.12 \%, 0.4 \%, 2.2 \%$, and $1.15 \%$ knew about bone settler, holy water, witchcraft, TBA and others respectively. Majority of the respondents reported that they heard about more than three types of TM. One hundred fifty one $(55.7 \%)$ of the respondent faced the patient who visited modern health care service after visiting TM practitioners. From those $106(70.02 \%)$ is because of no improvement while $18(11.9 \%)$ and $26(17.22 \%)$ is because of peer influence and side effects of the drugs respectively. One hundred forty nine $(60.08 \%)$ of the respondent mentioned the main source of the supply for herbal product was from practitioners, followed by neighbors $44(17.74 \%)$, relatives $28(11.3 \%)$, themselves $17(6.85 \%)$ and friends $10(4.03 \%)$.

Table 2. Knowledge about traditional medicine of the respondents, Jara Bale Zone, South east Ethiopia: April 2013.

\begin{tabular}{|c|c|c|}
\hline Variables & Frequency & Percent \\
\hline \multicolumn{3}{|l|}{ Have you ever heard about TM? } \\
\hline Yes & 261 & $96.3 \%$ \\
\hline No & 10 & $3.7 \%$ \\
\hline \multicolumn{3}{|l|}{ Which one do you know? } \\
\hline Herbal & 96 & $36.78 \%$ \\
\hline Bone Settler & 8 & $3.05 \%$ \\
\hline C. Holy Water & 16 & $6.12 \%$ \\
\hline D. Witch Craft & 1 & $0.4 \%$ \\
\hline E. TBA & 6 & $2.3 \%$ \\
\hline F. Other & 3 & $1.15 \%$ \\
\hline G. $A \& B$ & 6 & $2.3 \%$ \\
\hline H. A\&C & 15 & $5.74 \%$ \\
\hline I. A\&E & 8 & $3.06 \%$ \\
\hline J. B\&C & 3 & $1.2 \%$ \\
\hline K. $\geq 3$ Choices & 99 & $37.9 \%$ \\
\hline \multicolumn{3}{|l|}{$\begin{array}{l}\text { Have you come across patient who visited } \\
\text { modern health care service soon after visiting } \\
\text { TM practitioner? }\end{array}$} \\
\hline Yes & 151 & $55.7 \%$ \\
\hline No & 120 & $44.3 \%$ \\
\hline \multicolumn{3}{|l|}{ Why he/she did? } \\
\hline No Improvement & 106 & $70.2 \%$ \\
\hline Peer Influence & 18 & $11.9 \%$ \\
\hline Side Effect Of The Drugs & 26 & $17.22 \%$ \\
\hline Others & 1 & $0.66 \%$ \\
\hline \multicolumn{3}{|l|}{$\begin{array}{l}\text { What were the main sources of supply of herbal } \\
\text { product? }\end{array}$} \\
\hline From practitioners & 149 & $60.08 \%$ \\
\hline Relatives & 28 & $11.3 \%$ \\
\hline Neighbours & 44 & $17.74 \%$ \\
\hline Friends & 10 & $4.03 \%$ \\
\hline Themselves & 17 & $6.85 \%$ \\
\hline \multicolumn{3}{|l|}{ Why you use herbal medicines? } \\
\hline Fever & 89 & $30.8 \%$ \\
\hline Hypertension & 8 & $2.77 \%$ \\
\hline Diabetes & 7 & $2.42 \%$ \\
\hline Infectious/germs & 60 & $20.76 \%$ \\
\hline Constipation & 51 & $17.65 \%$ \\
\hline Rheumatism & 39 & $13.5 \%$ \\
\hline Others & 35 & $12.11 \%$ \\
\hline $\begin{array}{l}\text { What do you know about adverse effect of TM? } \\
\text { No adverse effects }\end{array}$ & 68 & $24.9 \%$ \\
\hline $\begin{array}{l}\text { Had adverse effects like; skin rash, vomiting, } \\
\text { dizziness }\end{array}$ & 148 & $54.21 \%$ \\
\hline Users experienced inexplicable adverse effects & & \\
\hline $\begin{array}{l}\text { Following the usage of herbal } \\
\text { medicine }\end{array}$ & 57 & $20.88 \%$ \\
\hline
\end{tabular}




\subsection{Attitude of Participants of the Study Towards Traditional Medicine}

One hundred nineteen $(43.91 \%)$ of the respondents have planned to use traditional medicine in the future and $152(56.08 \%)$ were not use traditional medicine because of access of modern medicine, $45(28.48 \%)$, fear of side effects $101(66.4 \%)$ and religion \& others 5(3.28\%). Among the respondents $88(32.47 \%)$ disagreed, $82(30.25 \%)$ agreed, 51(18.81\%) strongly disagreed, 26(9.6\%) neutral and $24(8.85 \%)$ strongly agreed the usage of traditional medicine among the community. one hundred seventy four $(64.2 \%)$ of the respondents were not encourage others to use traditional medicine and 97(35.8\%) were encourage others to use traditional medicine because of religion 19(19.58\%), cost $19(19.58 \%)$, availability $47(48.45 \%)$ and others $12(12.37 \%)$.

One hundred forty eight $(54.61 \%)$ of the respondents believe that there are disease that are not cured by modern medicine and $123(45.38 \%)$ think that there are no. Among the respondents $173(63.6 \%)$ suggest that herbal medicine users should consider herbal medicine is safe to use, 71(26.1\%) suggest believed otherwise and 28(10.3\%) suggest they were uncertain. Out of the respondents $163(60.15 \%)$ had negative attitude while $108(39.85 \%)$ had positive attitude towards traditional medicine. About 136(50.18\%) of the respondent accept traditional health practice while $135(49.8 \%)$ not accept.

Table 3. Community attitude about TM; Jara Bale Zone, Southeast Ethiopia; April 2013.

\begin{tabular}{|c|c|c|}
\hline Variables & Frequency & Percent \\
\hline \multicolumn{3}{|c|}{ Do you have planned to use TM In the future? } \\
\hline Yes & 119 & $43.91 \%$ \\
\hline No & 152 & $56.08 \%$ \\
\hline \multicolumn{3}{|l|}{ Why don't you have? } \\
\hline Access of modern medicine & 42 & $27.6 \%$ \\
\hline Fear of side effect & 101 & $66.4 \%$ \\
\hline Religion & 4 & $2.63 \%$ \\
\hline Others & 5 & $3.28 \%$ \\
\hline \multicolumn{3}{|l|}{$\begin{array}{l}\text { Do you agree the usage of TM among the } \\
\text { community? }\end{array}$} \\
\hline Strongly Agree & 24 & $8.85 \%$ \\
\hline Agree & 82 & $30.25 \%$ \\
\hline Neutral & 26 & $9.6 \%$ \\
\hline Disagree & 88 & $32.47 \%$ \\
\hline Strongly Disagree & 51 & $18.81 \%$ \\
\hline \multicolumn{3}{|l|}{ Do you encourage others to use TM? } \\
\hline Yes & 97 & $35.8 \%$ \\
\hline No & 174 & $64.2 \%$ \\
\hline \multicolumn{3}{|l|}{ Why do you encourage others to use TM? } \\
\hline Religion & 19 & $19.58 \%$ \\
\hline Cost & 19 & $19.58 \%$ \\
\hline Availability & 47 & $48.45 \%$ \\
\hline Others & 12 & $12.37 \%$ \\
\hline \multicolumn{3}{|c|}{$\begin{array}{l}\text { Do you think that there are diseases not cured by } \\
\text { modern medicine? }\end{array}$} \\
\hline Yes & 148 & $54.61 \%$ \\
\hline No & 123 & $45.38 \%$ \\
\hline \multicolumn{3}{|c|}{$\begin{array}{l}\text { How do herbal medicine users consider herbal } \\
\text { medicine? }\end{array}$} \\
\hline Herbal medicine safe to use & 173 & $63.6 \%$ \\
\hline Believed otherwise (without any reason) & 71 & $26.1 \%$ \\
\hline Were Uncertain & 28 & $10.3 \%$ \\
\hline Why herbal medicine is safe to use? & & \\
\hline
\end{tabular}

\begin{tabular}{lll}
\hline Variables & Frequency & Percent \\
\hline Their natural origin & 85 & $47.48 \%$ \\
Efficacy & 48 & $26.8 \%$ \\
Lack of adverse effects & 46 & $25.7 \%$ \\
Do you accept traditional health practice? & & \\
Yes & 136 & $50.18 \%$ \\
No & 135 & $49.8 \%$ \\
\hline
\end{tabular}

\subsection{Practice of the Study Subjects on Traditional Medicine}

Two hundred $(73.8 \%)$ of the respondents have used traditional medicine at least once in their life time and the rest $71(26.2 \%)$ did not use traditional medicine. From those who have you ever used traditional medicine, 121(44.8\%), $38(14.07 \%), 86(31.85 \%)$ and $26(9.59 \%)$ consumed drinkable, ingestible, ointment type and other types of traditional medicines respectively.

Among the respondents who have used the different forms of traditional medicine: $160(80 \%)$ of the respondents mentioned that the outcome was improved. While $9(4.5 \%)$ of them complained that the outcome was exacerbated and $31(15.5 \%)$ had no change. One hundred seventy three (63.84\%) of participants prefer modern medicine, 21(7.75\%) of them prefer traditional medicine while $77(28.41 \%)$ want to use both traditional and modern medicines equally.

From the total of household owners participated in the study who used traditional medicine because of its availability and affordability is $94(34.68 \%)$ and $33(12.18 \%)$ respectively; while others $144(53.14 \%)$ mentioned that to use modern medicine because of their awareness about it. Accordingly, $177(65.31 \%)$ interviewees have visited traditional medicine practitioners at least once in their life time and $94(34.69 \%)$ of them have not.

According to this study from those who have visited traditional medicine practitioners $101(45.9 \%)$ were herbalist which is the leading type of practitioners followed by 55(25\%), 30(13.64\%), 29(13.18\%), 2(0.9\%) and 3(1.37\%) visited bone settler, TBA, spiritual, which craft and other respectively.

Among individuals who have used traditional medicine $90(45 \%)$ were influenced by their relatives, $58(29 \%)$ by friends, $12(6 \%)$ by colleagues and $40(20 \%)$ were influenced by others. Eighty six $(85.14 \%)$ have taken herbal medicine alone while $8(7.92 \%)$ and $7(6.93 \%)$ have taken with other herbal and in combination with prescribed medicine respectively.

Table 4. Community Practice of TM; Jara Bale Zone, Southeast Ethiopia; April 2013.

\begin{tabular}{lll}
\hline Variables & Frequency & Percent \\
\hline Have you ever used TM? & & \\
Yes & 200 & $73.8 \%$ \\
No & 71 & $26.2 \%$ \\
Which one did you use? & 121 & $44.8 \%$ \\
Drinkable & 38 & $14.07 \%$ \\
Ingestible & 86 & $31.85 \%$ \\
Ointment Type & 26 & $9.59 \%$ \\
Others & & \\
So what was the outcome? & 160 & $80 \%$ \\
Improved & \\
\hline
\end{tabular}




\begin{tabular}{ll|l}
\hline Variables & Frequency & Percent \\
\hline Exacerbated & 9 & $4.5 \%$ \\
No Change & 31 & $15.5 \%$ \\
Which one do you prefer? & & \\
Tm & 21 & $7.75 \%$ \\
Mm & 173 & $63.84 \%$ \\
Both & 77 & $28.41 \%$ \\
Why do you prefer it? & & \\
Its Availability & 94 & $34.68 \%$ \\
Affordability & 33 & $12.18 \%$ \\
Others & 144 & $53.14 \%$ \\
Have you ever visited TM practitioners? & & \\
Yes & 177 & $65.31 \%$ \\
No & 94 & $34.69 \%$ \\
\hline
\end{tabular}

\section{Discussion}

This study has attempted to assess the knowledge, attitude and practice of the community about traditional medicine. Accordingly the results of the study showed that the proportion of male in the sample was higher when compared to the female. This is somewhat expected due to the head of family is the husband and at the time of interview house wives give chance for husband.

The age group of $19-28$ years formed the largest proportion $(28.4 \%)$ of the respondents. This is consistent with the study done in Dembia district. Of the total respondents, the majority $207(76.4 \%$ ) are married, this is in contrast to the study done in Dembia which is $37.9 \%$, this might be due to the fact that the current study was done on household owners. This study indicates that $28.4 \%$ of the respondent were primary school, $24.4 \%$ secondary school, $24 \%$ were higher education and the rest $23.2 \%$ were uneducated in contrast to our study result of the study done in northern Ethiopia reported that $46.9 \%$ of the respondents had attend tertiary education, $2.8 \%$ had only primary education and the rests are non educated [14].

Our study reveals that respondents who accept traditional medicine/ practice (50.18\%) and who didn't accept traditional health care practice $(49.8 \%)$ are almost equal, but on the study which was done in Arsi zone Shirka district showed that $71.4 \%$ of participant accepted traditional health care practice. When we compare our result with that of Shirka district, number of participants who accept and who did not are equal [13]. However, the study conducted in Bale Zone Odo-Bulu and Demaro districts are consistent with our result. That may be due to better modern health care service availability and awareness of the community about modern health care service. Reason for acceptance of traditional medicine practices by the respondents were due to its affordability and accessibility, religious perspectives and they believe that there are diseases that are not cured by modern medicine. But those who did not accept traditional medicine practices were due to fear of side effect, awareness about modern medicine and modern health care availability.

Furthermore, according to this study majority of the respondent $55.7 \%$ reported that they come to the modern health care institutions soon after visited modern health care service soon after visiting traditional medicine practitioners. This figure is almost consistent with a study conducted in Shirka district. The reasons behind this is as mentioned by the respondents were not show improvement $(69.9 \%)$ is the first followed by the side effect of the drugs (17.18\%) [13].

Most of our respondents mentioned that the reasons of using traditional medicines are; for general body pain relief (34.15\%), fever $(17.77 \%)$, diarrhea $(13.24 \%)$ and others have no specific reason $(13.94 \%)$ while the study done in Nigeria revealed that no specific reason $25.9 \%$, malaria $20.8 \%$, blood sugar level reeducation $16.2 \%$, general body pain relieve $4.6 \%$ and diarrhea $3.5 \%$. The present study shows that the major source of information about herbal medicine are retailers $(31.88 \%)$, their parents $(31.56 \%)$, herbal medicine practitioners $(17.5 \%)$, health professionals $(9.06 \%)$ and media $(1.56 \%)$. The same is true for the study that was done in Nigeria Lagos in which their parents $(29.7 \%)$, health professionals $(13 \%)$, herbal medicine retailers $(4.2 \%)$ and media $(3.5 \%)$ [15].

Less than half of the interviewed individuals $43.9 \%$ would like practice traditional medicine in the future. This result contrasts with the study done at Dembia in which almost all of the interviewed individuals would like to practice traditional medicine in the future. This might be due to the fact that nowadays access of modern medicine is high, fear of side effect and the community has awareness about modern medicine.

The large proportion of the respondents replied that there are diseases that cannot be cured by modern medicine and almost all of them mentioned liver disease, rabies and HIV/AIDS as an example. Over half $(54.21 \%)$ of the respondents believed that traditional medicine has adverse effects like: skin rash, vomiting and dizziness, no adverse effects $(24.9 \%)$ and the rest users experienced inexplicable adverse effects. But in the previous study in Nigeria, Lagos reported that the high proportion $(79.2 \%)$ of herbal medicine users believed that herbal medicines have no adverse effects and the rest of them $(20.8 \%)$ had experienced one or more adverse effects [15].

One hundred seventy three $(63.6 \%)$ of the interviewed individuals in this study showed that herbal medicine users consider herbal medicine is safe to use, believed otherwise $(26.1 \%)$ and were uncertain $(10.3 \%)$. This is consistent with the study conducted in Nigeria Lagos which revealed that $58 \%$ of herbal medicine users considered herbal medicine is safe to use, $22.9 \%$ believed otherwise and $19.1 \%$ were uncertain. Safeties of herbal medicines were attributed to their natural origin $(47.48 \%)$, efficacy $(26.8 \%)$ and lack of adverse effects $(25.7 \%)$ (15). This might be due to the fact that Nigeria is also one of the developing countries like that of Ethiopia.

The majority (73.8\%) of our respondents have used traditional medicine once at least in their life time. The highest proportion $(44.8 \%)$ of the respondents used drinkable form of herbal medicines followed by ointment type (31.85\%). This result is similar with the study that was conducted in Bale zone, Mana Angetu district. Most of the users mentioned that 
the outcome was improved (80\%), no change $(15.5 \%)$ and exacerbated $(4.5 \%)$. This result has an agreement with the study done in Shirka district, Arsi zone [13].

\section{Conclusion}

In the cross sectional study of Jara town, most of our respondents know traditional medicine especially herbal type and use it because of their belief that herbals are natural and the majority of them encourage others to use traditional medicine because of its availability. Many of the respondents found herbal medicine to be safe, effective and beneficial. Despite many of the respondents believe that herbal medicine rarely produce adverse effects, few of them experienced mildly and moderately. More than half of the participants have used traditional medicine at least once in their life time, in most cases drinkable type.

\section{References}

[1] Frederick AM, Abdelmoneim I. Legal status of traditional medicine and complementary/Alternative Medicine: WHO, worldwide review: Geneva, 2001.

[2] Daniel J, Caroline A, Nakanjako J. practical hand book for Anti malarial drug therapeutic efficacy testing for district health workers. Harare: WHO/AFRO, 1999.

[3] Ali K. M, Albert M, Andualem T. Traditional Medicine strategy 2002-2005. WHO, Geneva 7, WHsehO/EDM/2002.

[4] Olufunke A, Browyn H, Matthew C, Jane G. Utilization of traditional medicine, WHO fact sheet, Geneva, May 2003.

[5] Bannerman RH, Burton J, Chien W. Traditional medicine and Health care Coverage, WHO, Geneva, Switzerland 1993.
[6] Lambert J. Ethiopia; Traditional Medicine and the bridge to better health, World Bank Ethiop. J. Health Dev, 2006; 20(2).

[7] Central statistical Authority (CSA) and ORC Macro Ethiopia Demographic and Health Survey 2000, Addis Abeba (AA) Ethiopia and Calverton, Maryland, USA, May 2001.

[8] Micheal M. A brief history of Medicine, USA, January 4, 2009.

[9] Ketema A. Transitional Government of Ethiopia Health Sector Strategy. Addis Ababa, April 1995. Ethiop J. Health Dev 2006; 20(2).

[10] Hanbin W, Gao W. Assessment of the Pharmaceutical sector in Ethiopia. Federal Democratic Republic of Ethiopia, Ministry of Health, Addis Ababa, October 2003.

[11] Papadopoulos R, Lay M, Gebrehiwot A. Cultural Snapshots. A Guide to Ethiopia refugees for health care workers. Research center for Trans-Cultural Studies in Health. Middle sex University; London UK n144YZ, May 2002.

[12] Nigussie B. Traditional Wisdom and Modern development: A case study of traditional peri-natal knowledge among women in Southern Shewa, Ethiopia. Doctoral dissertation, University of Stockhelm, December 1988.

[13] Getachew A, Dawit A, Timotewos G, Kelbesa U. perception and practices of modern and traditional health practitioners about traditional medicine in Shirka district, Arsi zone, Ethiopia, February 1999.

[14] Gutu D, Melkie E, knowledge, attitude and practice involved in harmful health behavior in Dembia district, northwest Ethiopia, may 2001.

[15] Ibrahim A, Kazeem O and Mercy A. herbal medicine use among urban resident in Lagos, Nigeria, march 2011. 